\title{
Funções dos escritórios de projetos no desenvolvimento de produtos: pesquisa-ação em empresa de alta tecnologia
}

\author{
Sanderson César Macêdo Barbalho ${ }^{\mathrm{a} *}$, Jose Carlos de Toledo ${ }^{\mathrm{b}}$, \\ Junia Rojic ${ }^{c}$, Matheus de Aguiar Sillos ${ }^{\mathrm{d}}$ \\ a*sandersoncesar@unb.br, UnB, Brasil \\ btoledo@dep.ufscar.br, UFSCar, Brasil \\ junia.rojic@br.promonlogicalis.com, PROMON Logicalis, Brasil \\ dmatheus.sillos@gmail.com, OPTO ELETRÔNICA S.A., Brasil
}

\begin{abstract}
Resumo
0 artigo apresenta um escritório de projetos (PMO - Project Management Office) de uma empresa que desenvolve produtos baseada em práticas de gestão de projetos (GP) por ele suportadas. As práticas centralizam no PMO atividades que diferem das funções descritas na literatura como caracterizando sua atuação nos projetos. São realizadas funções de gestão de insumos: atividades que provêm os projetos com insumos necessários à montagem dos protótipos e produtos desenvolvidos. A composição das funções do PMO foi comparada com a bibliografia. São apresentados indicadores de eficiência e eficácia dos projetos. Houve redução dos lead-times de fabricação em $90 \%$ e de compras em 75\%. A duração dos projetos reduziu em 43\%. Sugere-se que a função assumida pelo PMO possa incrementar as opções teóricas para a estruturação de escritórios de projetos em desenvolvimento de produtos.

Palavras-chave
\end{abstract}

Desenvolvimento de novos produtos. Gestão de projetos. Escritórios de projetos.

\section{Introdução}

0 escritório de projetos, do inglês Project Management Office (PMO), é a estrutura organizacional estabelecida para facilitar as atividades da gestão de projetos (GP) e trazer melhorias ao próprio processo de gestão da organização por meio da gestão do portfólio e do alinhamento de projetos com a estratégia corporativa (CRAWFORD, 2002). Os PMOs se originaram em meados da década de 1960 nos grandes projetos militares, aeroespaciais e de construção civil. Do final da década de 1970, até meados da década de 1980, com o surgimento dos primeiros softwares de gestão de projetos, o escritório de projetos expandiu seu escopo de atuação para projetos de diferentes áreas de conhecimento.

Na segunda metade da década de 2000 proliferaram estudos e publicações enfocando os escritórios de projetos como estruturas organizacionais adequadas para a implementação de programas de mudança organizacional, sejam elas conduzidas com base em planejamento prévio, sejam baseadas na própria evolução da empresa. Destacam-se os trabalhos da Escola de Montreal, onde estudos como os de Hobbs e Aubry (2007), Aubry, Hobbs e Thuillier (2007), Hobbs, Aubry e Thuillier (2008), Aubry et al. (2010b), apontam para a multiplicidade de funções exercidas pelos PMOs, assim como para a importância destes para a mudança organizacional. Tal multiplicidade de funções, entretanto, demonstra que os PMOs analisados têm enfoque em atividades de monitoramento e controle dos projetos, reporte para a gerência sênior e desenvolvimento de metodologias de gestão de projetos.

Este artigo apresenta e analisa o caso de um escritório de projetos em uma empresa de base tecnológica localizada no interior do estado de São Paulo. A empresa desenvolve produtos 
cuja tecnologia básica é bastante diversificada, o que exige dos gerentes de projeto uma forte especialização técnica. Nesse contexto, o PMO da empresa assumiu funções de gestão dos insumos necessários à consecução dos projetos, além de atividades relacionadas à gestão de multiprojetos. São apresentados o procedimento de gestão utilizado e os resultados conseguidos. 0 período analisado no artigo, dezembro de 2005 a dezembro de 2008, consiste numa faixa temporal na qual os procedimentos descritos foram implantados na empresa. Foi o intervalo no qual o PMO estava se consolidando e, portanto, configurando seus processos e estabelecendo procedimentos de gestão necessários a controlá-los. Espera-se com o estudo contribuir para o delineamento das funções dos PMOs que servem as áreas de inovação e desenvolvimento de produtos nas organizações.

Do ponto de vista metodológico, o trabalho se configura como uma pesquisa-ação, segundo critérios de Thiollent (1997). Emergiu de uma integração entre o pessoal envolvido com as práticas de gestão de projetos na empresa e um grupo de pesquisa em GP de uma universidade brasileira. Do ponto de vista técnico, os dados são primários, cedidos pela empresa e complementados por meio de observação participante (SERVA; JAIME JÚNIOR, 1995). Uma vez que se trata da descrição de práticas em uma empresa apenas, pode-se classificá-lo como estudo de caso holístico, segundo Yin (2004).

A seção seguinte apresenta os fundamentos teóricos do trabalho: um sumário da teoria sobre o desenvolvimento de produtos e a fundamentação sobre escritório de projetos. A seção 3 mostra detalhes dos procedimentos metodológicos utilizados, a seção 4 descreve as práticas de gestão de projetos implementadas pelo escritório de projetos. A seção 5 apresenta um comparativo entre o escritório analisado e as funções reportadas na literatura como papéis desempenhados por PMOs e a seção 5 apresenta as considerações finais do trabalho.

\section{0 desenvolvimento de produtos e os PMOs}

\subsection{Processo de desenvolvimento de produtos}

Pugh (1990, p. 5) apresenta a seguinte definição para o processo de desenvolvimento de produtos (PDP):

[...] é a atividade sistemática necessária, da identificação de necessidades de mercado e usuário até a venda do produto, que atenda com êxito a essas necessidades. Trata-se de uma atividade que abrange produto, processos, pessoas e organização.
Pugh (1990) discute as diferenças entre o que chama de projeto parcial (partial design) e projeto total (total design), este último sendo o próprio processo de desenvolvimento de produtos. 0 projeto parcial seria o enfoque dado nas diferentes áreas da engenharia que interagem no projeto técnico de um novo produto. Clark e Fujimoto (1991) enfatizam o caráter informacional desse processo, ou seja, o fato de os insumos e resultados básicos do desenvolvimento de produtos serem informações, em contraposição à manufatura, cujos resultados são bens e/ou serviços. A definição sugere ainda que os dados de entrada do PDP provêm de duas fontes básicas: do mercado e da tecnologia.

Cooper (2001) identifica o PDP como algo que pode ser mais formal ou mais informal dentro de uma empresa, mas que de fato existe, mesmo que não formalizado. 0 modelo do autor (denominado Stage-gate) advoga que o PDP deve ser entendido como um balanceamento adequado de atividades realizadas nos estágios ou fases (stage) com decisões efetivas realizadas entre eles (gates). No início do século XXI tem amadurecido o entendimento de que a gestão do desenvolvimento de produtos deve ocorrer ao longo de todo o ciclo de vida dos produtos comercializados por uma empresa (CHRISSIS et al., 2003).

Rozenfeld et al. (2006) argumentam que o processo de desenvolvimento de produtos é operacionalizado através de projetos distintos, conforme apresentado na Figura 1.

Segundo os autores, um modelo de referência seria um processo sistematizado e documentado, o qual permite que as particularidades de cada projeto e equipe de desenvolvimento sejam atendidas. Considerando o campo profissional da gestão de projetos, o PMBOK (PROJECT..., 2012) estabelece os processos necessários ao gerenciamento de projetos, os quais podem ser utilizados em projetos de desenvolvimento de produtos, muito embora

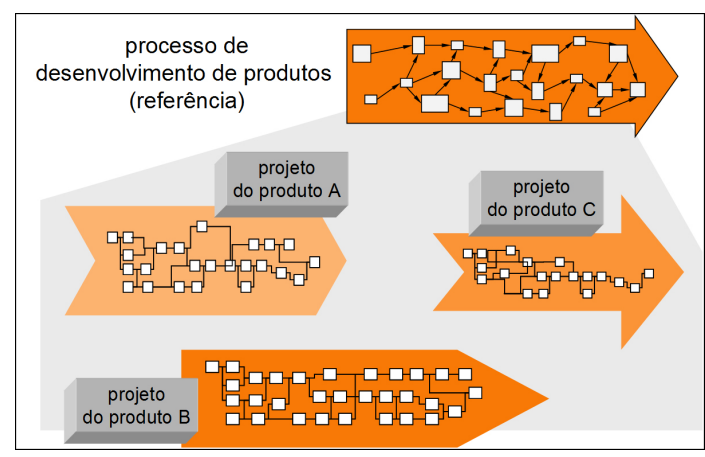

Figura 1. Projetos distintos resultantes de um mesmo processo. Fonte: Rozenfeld et al. (2006, p. 42). 
estudos recentes reportam que há muitas lacunas no referencial do PMBOK quando aplicado ao PDP (PONS, 2008). Tais lacunas não serão aqui discutidas, mas um dos conceitos pouco elaborados no PMBOK é, exatamente, o de escritório de projetos.

\subsection{Escritórios de projetos}

Para Crawford (2002), um escritório pode ser simples, com poucas pessoas preparando e mantendo cronogramas, ou estruturas complexas com várias pessoas realizando atividades de planejamento, controle de informações e monitoramento de projetos. 0 modelo de PMO, sugerido pela autora, classifica os escritórios de projetos segundo níveis amplamente adotados na bibliografia da área (Figura 2).

O PMO de nível 1 é característico de grandes e complexos projetos únicos, sendo totalmente voltados ao projeto que o criou. 0 nível 2, destinado a uma unidade de negócios específica, tem a importante característica de realizar a gestão de recursos da unidade; assim, é necessário criar métricas para priorização dos vários projetos existentes no departamento que competem por recursos entre si. 0 nível 3 realiza trabalho similar ao anterior, no entanto é estendido a todas as unidades de negócio da organização.

Dai e Wells (2004) compararam práticas de gestão de projetos em empresas americanas de diversos setores com e sem PMOs. Os autores identificaram práticas mais efetivas de GP nas empresas com PMOs, especialmente quanto ao registro de lições aprendidas e à aplicação de metodologias e técnicas de GP. Martins et al. (2005) analisaram práticas estabelecidas por um PMO no contexto da fusão de empresas de telefonia celular no Brasil e demonstram como as funções e responsabilidades do escritório de projetos foram sendo incrementadas ao longo do tempo em função dos resultados alcançados no desempenho dos projetos, assim como do suporte da alta gerência na demarcação do espaço político do PMO dentro da empresa.

Rodrigues; Rabechini Jr. e Csillag (2006) realizaram estudo descritivo que enfoca a relação entre PMOs e a maturidade da GP nas empresas. Os autores observam que os PMOs pesquisados apresentam baixo grau de aderência aos modelos teóricos estabelecidos. Maximiano e Anselmo (2006) estudaram a implantação de um escritório de projetos em uma grande empresa da área de telefonia e identificaram que há uma lacuna no que concerne à inexistência de metodologias apropriadas à quantificação do valor de um PMO.

Hobbs e Aubry (2007) realizaram extenso estudo analítico acerca das atividades dos PMOs. Foram analisadas a presença e o grau de importância de 27 diferentes funções e papéis atribuídos aos PMOs. Essas funções e papéis foram agrupados com base em análise fatorial gerando os seguintes grupos: (1) atividades de monitoramento e controle do desempenho dos projetos - MONCON; (2) desenvolvimento de competências e metodologias de gestão de projetos - METCOMP; (3) gerenciamento multiprojeto - MULT1; (4) gestão estratégica - ESTRAT; e (5) aprendizagem organizacional - ORGLEARN. Os autores identificaram, ainda, outras atividades consideradas importantes pelos responsáveis pelos PMOs pesquisados, mas que não foram agrupadas por razões de coerência conceitual: (6) execução de tarefas especializadas para os gerentes de projeto - ESPEC; (7) gerenciar as interfaces com clientes - CLIENT; e (8) recrutar, selecionar, avaliar e determinar salários dos gerentes de projeto - RECHUM. Os autores consideram que a dificuldade conceitual relacionada aos PMOs tem base no fato de os PMOs serem fenômenos relativamente recentes, existir uma grande variedade de formas e funções para eles e não haver investigação mais sistemática a respeito. Os autores estudaram 500 PMOs canadenses, americanos e australianos. $\mathrm{Na}$

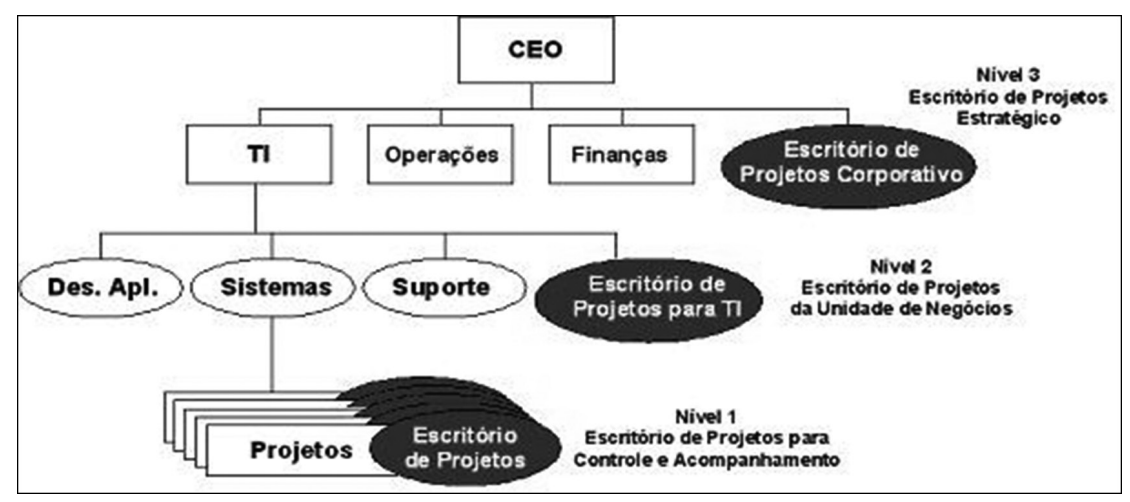

Figura 2. Níveis de atuação do escritório de projetos (CRAWFORD, 2002). 
média as atividades de monitoramento e controle do desempenho dos projetos são as mais importantes dentro dos PMOs, segundo seus gestores.

Aubry, Hobbs e Thuillier (2007) consideram que a pesquisa em gestão de projetos tem comumente apresentado dificuldades no que tange ao entendimento de como os PMOs devem ser concebidos e gerenciados em empresas que não trabalham exclusivamente com projetos para atender a seus objetivos de negócio. Para os autores, os PMOs são estruturas que conectam múltiplas dimensões de uma organização e como tais não devem ser avaliados apenas quanto a prazos, custo, escopo e desempenho, mas também quanto à coesão e moral das equipes e ao alinhamento estratégico dos projetos. Castro e Carvalho (2007) realizaram um estudo de casos múltiplos em empresas de telecomunicações brasileiras nas quais há efetivo uso de práticas de GP, inclusive com implantação de PMOs. Os autores observaram uma lacuna quanto à aferição dos resultados das práticas de $\mathrm{GP}$ em todas as empresas pesquisadas, mesmo nas que contavam com PMOs.

Hobbs, Aubry e Thuillier (2008) analisaram PMOs como elementos de inovação organizacional. Pesquisando a trajetória de 11 PMOs ao longo de 10 anos, os autores verificaram que as empresas reconfiguram seus escritórios a cada 3 ou 4 anos motivadas por eventos do contexto social da empresa, eventos internos, filosofia de gestão ou tensões internas. Pellegrinelli e Garagna (2009) demonstram que o sucesso do PMO traz um risco iminente de que ele seja considerado desnecessário, à medida que ele consolide o uso de metodologias e ferramentas de GP na empresa. Assim, os PMOs deveriam buscar continuamente gerar novos valores com seus serviços por meio da redefinição de seus propósitos e objetivos na empresa. Aubry et al. (2010a) apresentaram estudo de casos múltiplos sobre os direcionadores de mudança nas atividades dos PMOs. Segundo os autores, transições são comuns e necessárias aos PMOs, podendo representar a relevância dos mesmos para o desenvolvimento da organização.

Bredillet (2010) considera que o aspecto organizacional da GP é uma das principais questões abertas a pesquisas na área, especialmente quanto ao papel dos PMOs habilitando e executando processos de mudança organizacional. Aubry et al. (2010b) apresentam resultados de um survey cujo objetivo foi levantar os principais motivadores das transições nas funções executadas pelos PMOs, nas organizações de maneira geral, sejam eles do contexto interno ou externo à empresa. Aubry e Hobbs (2011) discutem quais perspectivas de desempenho organizacional são mais fortemente relacionadas aos PMOs, tendo verificado que, dependendo do enfoque dado ao desempenho organizacional pela própria corporação, o papel do PMO é alterado de maneira a alinhar seus resultados às demandas da empresa.

Alves et al. (2012) realizaram análise em 51 PMOs de diferentes setores da economia brasileira estudando a implantação dos escritórios de projetos. Os autores analisaram um conjunto de 15 melhores práticas extraídas da literatura científica chegando à conclusão que os seguintes elementos têm maior impacto sobre 0 sucesso da implantação dos escritórios: obter patrocínio da alta administração, reconhecer a implantação como uma mudança cultural, não reinventar a roda - utilizar as lições aprendidas, conhecimento e procedimentos existentes, não esquecer nenhuma das partes interessadas (stakeholders) chave e alocar no PMO profissionais sêniores e experientes.

\subsection{Consolidação do referencial teórico}

Observa-se, de maneira geral, que há um esforço de pesquisa acerca da dinâmica dos PMOs. Pode-se concluir que os estudos apontam para o fato de tais estruturas serem posicionadas na interface de diversas entidades organizacionais, algumas ligadas aos projetos e outras ligadas às operações, o que os tornam centro de numerosas perspectivas de desempenho organizacional. Na literatura de desenvolvimento de produtos, Clark e Fujimoto (1991) discutem o PMO como unidade organizacional necessária em estruturas matriciais cuja responsabilidade seria agregar informações acerca de todos os projetos que estão em curso e permitir a troca de informações entre projetos. Rozenfeld et al. (2006), por sua parte, demonstram a importâncias das práticas de gestão de projetos ao longo do PDP e apresentam os escritórios de projetos como áreas funcionais especializadas em planejamento cuja função é apoiar o gerente de projeto. Portanto, dentre as práticas de GP no desenvolvimento de produtos, tem-se os PMOs como uma função de suporte em planejamento.

Assim, por um lado, nas publicações sobre gestão de projetos há uma lacuna acerca da análise de características e desempenho de escritórios de projetos focados em desenvolvimento de produtos e projetos de inovação; enquanto na bibliografia específica da área de desenvolvimento de produtos, há pouca menção ao papel dos PMOs na condução de projetos de novos produtos. De maneira geral, os aspectos de suporte gerencial, metodológico e de monitoramento e controle dos projetos são enfatizados nas publicações. Tal ênfase caracteriza um distanciamento sistemático dos escritórios quanto às tarefas que agregam valor ao projeto, ou seja, àquelas que estão na estrutura da divisão do trabalho do projeto e constam nos 
seus cronogramas como atividades necessárias à consecução dos mesmos.

É importante salientar que, sob o ponto de vista teórico, esse trabalho se relaciona à discussão sobre as funções e papéis exercidos pelos PMOs, conforme a linha de trabalho de Hobbs e Aubry (2007), enfocando, entretanto um PMO que atende ao PDP em uma empresa de alta tecnologia.

\section{Aspectos metodológicos}

A pesquisa-ação constitui-se num procedimento científico por meio do qual se conseguem testar aplicações de outros resultados de pesquisa. Mais ainda, a pesquisa-ação é recomendada para novas abordagens, onde o pesquisador necessita explorar novas ideias e criar um conhecimento a ser testado na prática (COUGHLAN; COUGHLAN, 2002). Esse era o contexto teórico-prático do início do trabalho ora apresentado em meados de 2005, quando a empresa pesquisada se viu diante de um forte crescimento da área de projetos. Por um lado aumentou o número de projetos em andamento, por outro, a complexidade dos projetos demandava que houvesse maior especialização dos engenheiros mais experientes e, portanto, a gestão dos projetos carecia de uma sistemática mais robusta para a consecução dos prazos a custos competitivos.

Optou-se por constituir um escritório de projetos e na época, final de 2005, o referencial mais próximo era a discussão proposta por Clark e Fujimoto (1991), as diretrizes do PMBOK quanto às funções dos PMOs e, logo após, as diretrizes propostas por Rozenfeld et al. (2006). Tais referências davam enfoque na função de suporte dos PMOs. Entretanto, verificou-se que, por um lado, esse enfoque de suporte metodológico dificultava o acesso do PMO às equipes de projeto propriamente ditas, as quais viam o escritório como uma terceira parte não envolvida com os problemas práticos do projeto. Por outro, fazia com que o conhecimento em gestão de projetos desenvolvido pelos profissionais do PMO não fosse utilizado diretamente no gerenciamento de aspectos críticos dos projetos, desperdiçando o potencial de melhoria representado por uma possível atuação do PMO diretamente na gestão dos mesmos.

Essa constatação levou a equipe responsável pelo PMO a buscar alinhar sua atuação a aspectos que representassem demandas críticas dos projetos. 0 objetivo era reduzir as tensões que poderiam resultar de o PMO realizar cobranças acerca de prazos e custos e não contribuir para a consecução dos mesmos em um ambiente caracterizado pela mudança constante.

Em meados de 2007, as primeiras publicações da Escola de Montreal trouxeram uma reflexão mais sistemática sobre o papel dos escritórios de projetos em função não só de sua posição na hierarquia organizacional, mas também da forma como os projetos eram executados na empresa e da relação entre o escritório e os gerentes de projeto. A multiplicidade de funções apresentada especialmente em Hobbs e Aubry (2007) abriram novas perspectivas teóricas para a equipe envolvida no escritório, o que contribuiu para o avanço do formato já delineado no ano anterior.

Thiollent (1997) aponta para a necessidade de controle da subjetividade ao longo da pesquisa-ação de maneira a impedir que as sensações, emoções e compromissos pessoais dos pesquisadores enviesem as conclusões científicas do trabalho. Em geral, os aspectos subjetivos relacionados à presença do pesquisador como participante da ação ora relatada foi assim mitigado: (1) pelo enfoque na interpretação de dados primários dos processos analisados - a equipe orientou seu trabalho para a adoção de indicadores de desempenho que permitissem avaliar, mesmo que indiretamente, os processos implementados; (2) pela discussão em grupo para subsidiar as análises realizadas de maneira que as impressões subjetivas de cada membro do grupo eram debatidas pelos demais antes de serem incorporadas na análise final; e (3) pela participação de um pesquisador externo ao grupo e ao processo de melhoria via pesquisa-ação, o que permitiu ainda mais mitigar a subjetividade do grupo, especialmente no que tange ao "pensamento grupal” (BARON et al., 2011).

Ao longo do trabalho foram utilizados cadernos de anotações onde eram registradas as informações necessárias, reuniões de planejamento e resultados intermediários da implantação do escritório. A análise foi realizada por meio de textos confeccionados pela equipe de pesquisadores acerca das medidas aferidas para os indicadores construídos. Os textos eram preparados para compor relatórios gerenciais periódicos. Sua análise com base no referencial teórico apresentado neste artigo, e mediante uma sistemática busca por mitigar a subjetividade de cada pesquisador envolvido, é apresentada neste texto.

\section{Descrição das práticas de gestão do escritório de projetos}

\subsection{Caracterização da empresa}

A empresa pesquisada está localizada em um polo tecnológico no interior de São Paulo. Completou, em 2011, 25 anos de história, tendo sido pioneira no Brasil no desenvolvimento e fabricação de Laser Hélio-Neônio. A evolução dessa tecnologia levou à 
miniaturização e o domínio dessas novas tecnologias permitiu à empresa desenvolver aplicações para a área de medicina, especialmente voltada à oftalmologia.

A tecnologia laser tem fortes aplicações militares e logo aproximou a empresa do Centro Tecnológico da Aeronáutica (CTA) ainda nos anos 90. A proximidade com o Instituto Nacional de Pesquisas Espaciais (INPE) através dos relacionamentos construídos junto ao CTA fez com que em 2004 a empresa se tornasse uma das principais fornecedoras do Programa Espacial Brasileiro, com o desenvolvimento de câmeras de monitoramento ambiental.

A empresa compõe-se de quatro diretorias: filmes finos, pesquisa e desenvolvimento, diretoria comercial e diretoria de manufatura. Cada diretoria tem como diretor um dos sócios proprietários da empresa. A diretoria de "pesquisa e desenvolvimento" (P\&D) é responsável pelo projeto dos equipamentos médicos, aeroespaciais ou militares. Ela é composta de um grupo de engenharia formado por engenheiros mecânicos, eletrônicos, de software e físicos e por um grupo de montagem especializada, composto por técnicos em eletrônica e mecânica, responsável pela integração dos equipamentos desenvolvidos. Ela utiliza serviços especializados das áreas de filmes finos e de manufatura.

A organização e a gestão do processo de desenvolvimento de produtos inovadores têm sido planejadas e executadas pela diretoria de P\&D da empresa com o suporte do escritório de projetos. Os procedimentos de gestãode projetos utilizados pelo PMO serão apresentados na próxima seção.

\subsection{Estrutura e práticas de gestão de projetos da empresa: constituição do PMO}

Desde sua constituição, no ano de 2005, o PMO da empresa buscou enfocar atividades que tinham impacto nos tempos incorridos para a consecução dos projetos. lsso se deveu ao perfil dos projetos desenvolvidos pela empresa, cujo conteúdo tecnológico e as margens de lucro permitidas pelos produtos faziam com que os aspectos de tempo fossem os que mais incorriam em riscos de insucesso. Estavam previstas multas por atraso nos contratos.

Adicionalmente, dois aspectos do contexto organizacional trouxeram forte impacto no modelo de GP adotado pela empresa: (1) a empresa adota uma estrutura funcional para o seu PDP, o que implica que cada departamento gerencia seus prazos e prioridades com forte independência em relação aos demais; e (2) o departamento de $\mathrm{P} \& \mathrm{D}$ é responsável pela consecução dos projetos e, embora controle os prazos de suas equipes de engenheiros, não tem controle sobre as atividades de manufatura que impactam nos prazos de projeto. A partir de janeiro de 2005, por força dos novos projetos contratados na época, passou-se a sistematizar as interfaces do P\&D com as áreas de manufatura, o que se considerou imprescindível para atender os prazos dos projetos, uma vez que a estrutura funcional e a cultura existente geravam risco de multas contratuais.

\subsection{Procedimento de trabalho do PMO}

A Figura 3 sintetiza os procedimentos implementados para a gestão do fluxo de informações e materiais entre o PMO, as equipes de projetos do P\&D e os departamentos de manufatura: (1) confecção e gestão dos cronogramas dos projetos; (2) gestão de itens fabricados para os projetos; e (3) gestão dos itens comprados e aquisições em geral para os projetos. Cada um desses processos foi modelado, formalizado em ferramentas gerenciais e passou a ser monitorado quantitativamente por meio de indicadores de desempenho.

O PMO realizava acompanhamento junto aos gerentes de projetos de maneira a atualizar o plano de trabalho de cada projeto em andamento. Esse plano de trabalho tem no cronograma sua principal ferramenta

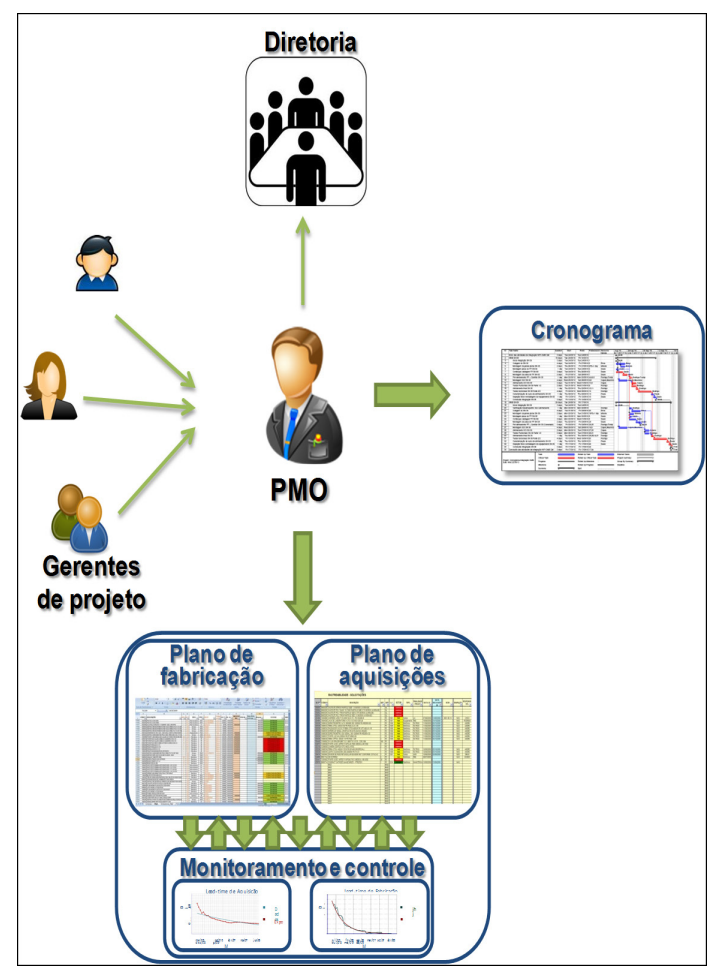

Figura 3. Procedimento de gestão de prazos dos projetos centralizado no PMO. 
para a programação das atividades interdepartamentais realizadas pelo PMO. Consolidados os cronogramas de todos os projetos, o gestor do PMO discute, junto à diretoria de $\mathrm{P} \& \mathrm{D}$, as intersecções entre eles do ponto de vista de recursos de fabricação e aquisições, aí incluindo máquinas e horas-homem de trabalho, e recursos financeiros para pagamento de itens comprados. As prioridades e reprogramações são estabelecidas nessas reuniões com a diretoria, nas quais os gerentes de projeto participam quando necessário. Como resultado, têm-se os planos de fabricação e de aquisições para o período considerado, assim como o cronograma congelado de cada projeto. 0 detalhe dessa sistemática será discutido a seguir.

\subsubsection{Gestão de cronogramas dos projetos}

Do ponto de vista de planejamento, a principal característica da metodologia de gerenciamento de projetos na empresa era a gestão do cronograma ser responsabilidade do PMO. 0 procedimento de gestão é ilustrado na Figura 4. Os cronogramas eram atualizados trimestralmente pelo PMO por meio de reuniões de acompanhamento com as equipes de projeto. Um cronograma padrão era utilizado, nele constando uma lista de atividades, com precedências e durações baseadas no histórico de projetos da empresa. Juntamente com a equipe do projeto, o PMO realizava uma análise crítica desse cronograma padrão de maneira a consolidar um cronograma inicial específico para cada projeto.
Uma vez consolidado, era salvo um baseline do projeto e congelada uma versão em formato não editável. Tal versão era enviada à equipe de projeto e publicada em um painel de projetos, além de discutida pela equipe e o PMO junto à diretoria de $P \& D$. Essa versão congelada era utilizada para alimentar uma planilha Excel na qual todos os cronogramas congelados podiam ser comparados. 0 objetivo de manter tal planilha era gerar indicadores de gestão do tempo relacionados às comparações entre planejado e executado, assim como a sistematização da duração dos projetos.

0 cronograma padrão continha, adicionalmente, datas relacionadas aos marcos intermediários que foram consolidados à medida que amadurecia a metodologia de gestão de projetos implementada pelo PMO. Assim, definiu-se que todos os projetos deveriam ser desenvolvidos mediante a construção dos seguintes protótipos: (1) de bancada, ou conceitual, cujo objetivo era validar o princípio de funcionamento do equipamento, especialmente funções primárias; (2) de engenharia, no qual todos os requisitos funcionais eram testados; (3) de qualificação, sobre o qual eram realizados todos os testes não funcionais necessários por regulamentação governamental ou de mercado. A conclusão dos testes com esses três tipos de protótipos representava os marcos principais dos projetos, os quais indicavam que uma fase havia sido concluída. Os protótipos eram então os principais resultados práticos perseguidos pelas equipes de projeto e, portanto, direcionavam o esforço de desenvolvimento.

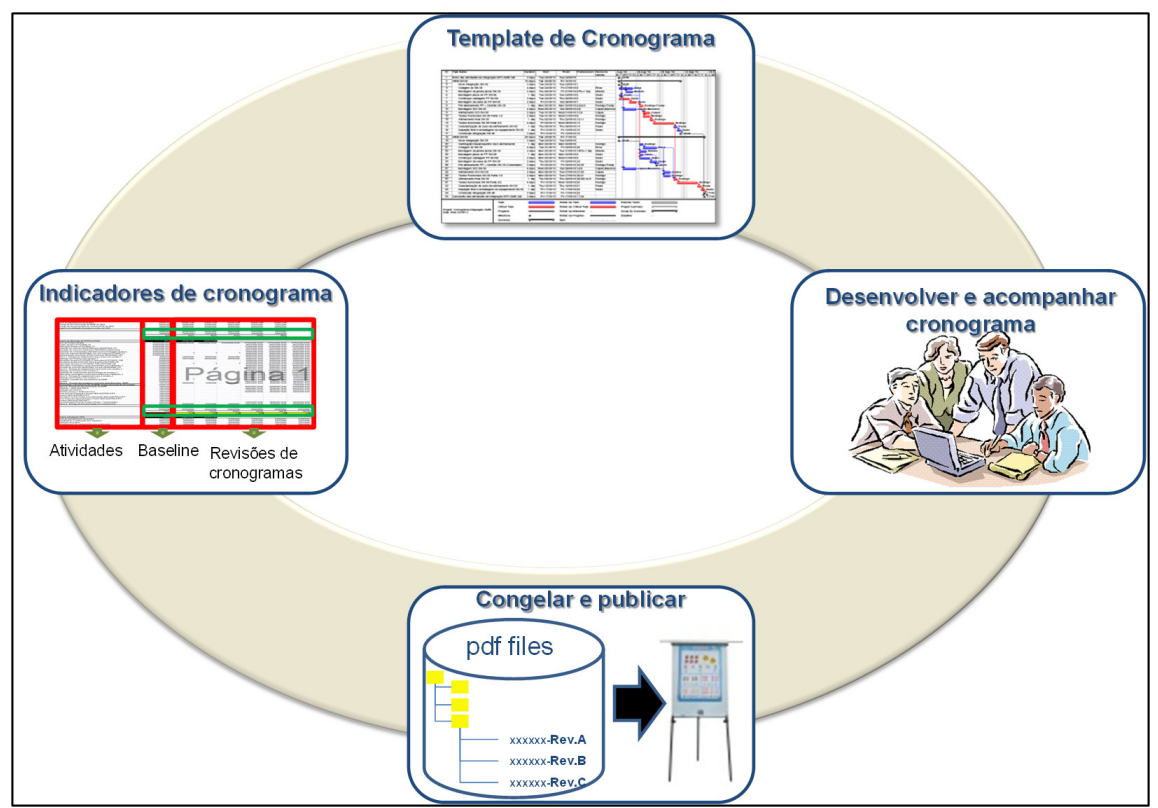

Figura 4. Procedimento de gestão de cronogramas centralizado no PMO. 
As datas estabelecidas nos cronogramas eram monitoradas com base no cumprimento desses marcos. Reuniões mensais eram realizadas pelo PMO com cada equipe de projetos de maneira a verificar o andamento das atividades, tanto de projeto (elaboração de especificações) quanto de fabricação ou de aquisições. Dependendo da criticidade das atividades e do seu nível de atraso, realizava-se uma reunião com a diretoria de forma a identificar linhas de ação alternativas. Ao final de três meses era rodado um novo ciclo de atualização dos cronogramas dos projetos, com uma nova versão congelada, divulgada aos stakeholders e comparada ao baseline original do projeto.

\subsubsection{Gestão da fabricação de itens para os projetos}

Do ponto de vista da gestão de fabricação de itens para os projetos, o PMO realiza a coordenação de ordens de fabricação de itens mecânicos e ópticos e, adicionalmente, de fabricação subcontratada. Tal processo foi mapeado considerando as possibilidades de fabricação mais críticas, incluindo aí processos especiais. Esse procedimento permitiu a sistematização da gestão de peças fabricadas através de ferramentas em Excel, do sistema ERP (Enterprise Resource
Planning) da empresa e serviços de e-mail integrado ao ERP. Tal processo está representado na Figura 5.

Com base nas datas estipuladas nos cronogramas construídos conforme o procedimento já apresentado, e mediante a liberação de especificações por parte dos engenheiros de projeto, o PMO repassava as ordens de fabricação para a fábrica ou para os fornecedores de peças e processos terceirizados. 0 responsável por cada departamento envolvido com o fluxo de peças foi encarregado de alimentar o sistema com a informação da data de término de sua atividade no fluxo. A composição entre sua data de término e a data da atividade anterior permitia calcular o lead-time das suas atividades para cada peça. Indicadores de lead-time foram consolidados para cada etapa do processo e compunham metas de produtividade para o processo como um todo. Além de alimentar o sistema com novas ordens de fabricação, o PMO era responsável por gerenciar as prioridades entre os recursos que apresentassem restrições em um determinado momento.

Ao PMO, nesse caso, foi incumbida a responsabilidade por garantir a consecução de todas as atividades e a alimentação do sistema pelos departamentos, assim como por gerenciar os indicadores de desempenho do processo. Já os gerentes de projeto eram responsáveis por garantir

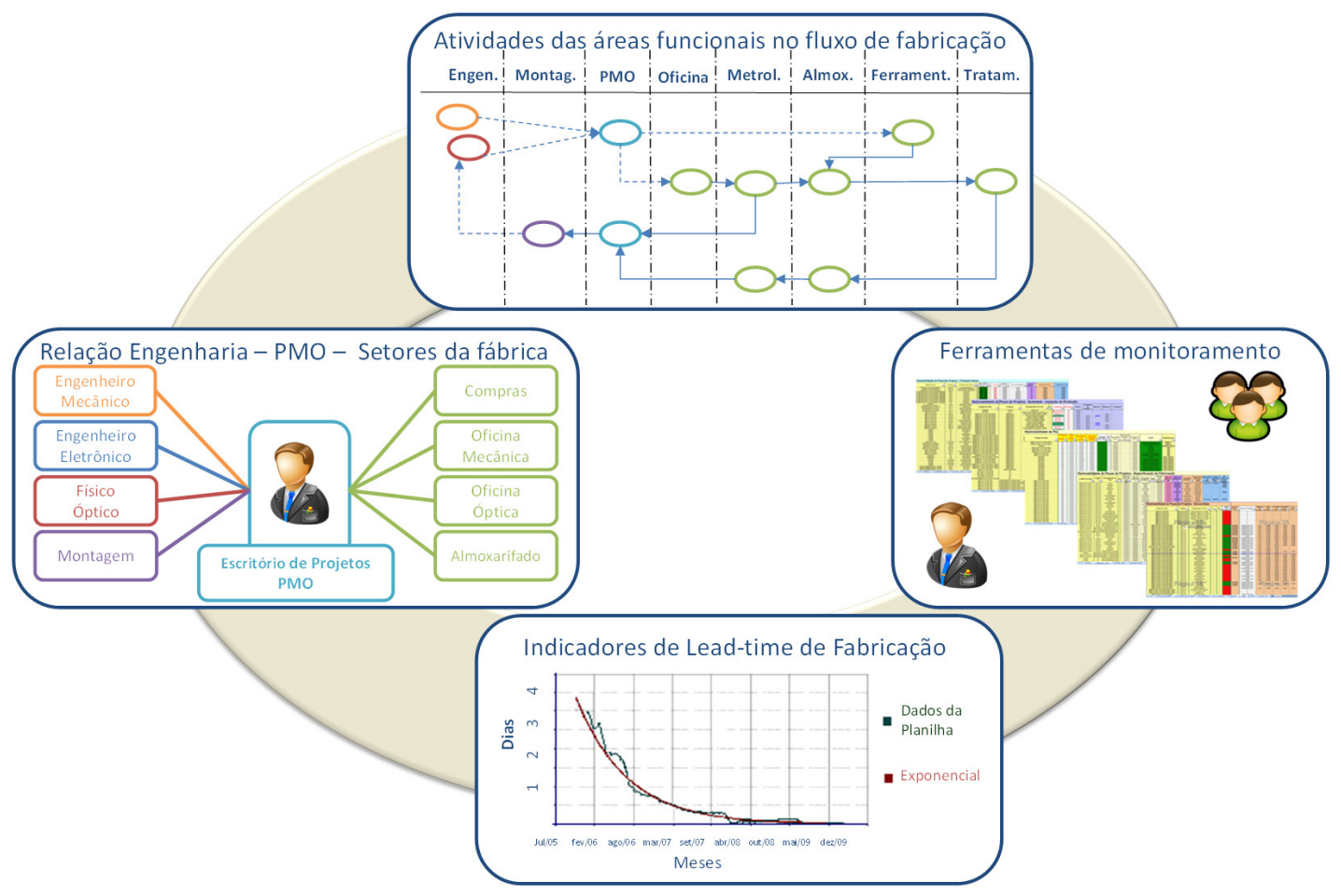

Figura 5. Esquema/estrutura de gestão de itens fabricados internamente ou terceirizados para os projetos. 
que suas equipes cumprissem os prazos estipulados nos cronogramas para a liberação de desenhos de fabricação, e cobravam o PMO acerca do andamento e dos prazos de entrega de suas peças.

\subsubsection{Gestão das aquisições necessárias aos protótipos de novos produtos}

0 gerenciamento de aquisições compreende a compra de itens nacionais e importados a serem usados nos projetos contratados. Assim como o gerenciamento de itens fabricados, o processo de compras foi mapeado considerando as possibilidades mais críticas de itens nacionais subcontratados e itens importados com longo lead-time. 0 processo foi também sistematizado através de ferramentas em Excel e Access, do sistema ERP da empresa e de serviços de e-mail integrado ao ERP.

Se comparado ao fluxo de fabricação de peças, o processo de compras é executado por menos departamentos. Cada departamento foi também responsabilizado por alimentar o sistema com a informação da data de término de sua atividade no fluxo de maneira a ser possivel identificar os lead-times intermediários do processo. A especificidade do processo de compras abrange também o estabelecimento da sua rastreabilidade, uma vez que a terminologia da compra se altera de um departamento para outro.
Inicia-se com uma solicitação de compra (SC) da engenharia, passando a um pedido (PD) para o departamento de compras, e um purchaseorder (PO) com pro-formainvoices $(\mathrm{PI})$ relacionadas, embarques e numerários para o departamento de comércio exterior. Para o financeiro são contas a pagar baseadas em notas fiscais de entrada (NF). Todas essas atividades faziam uso de módulos do sistema ERP da empresa, os quais, por motivos que fogem ao escopo deste artigo, não eram integrados totalmente de maneira a gerar informações sobre o estado da compra, previsões de entrega, custos totais e lead-times.

Para permitir a melhoria do processo e a rápida visualização da situação das compras, foram mapeadas todas as etapas do processo e foi formatado um relatório de processo utilizando datas e calculando lead-times intermediários. Foi também confeccionado um fluxo de valor agregado do processo com o cálculo de tempos de operação e de fila para cada etapa. Dessa forma foi possível estabelecer o plano de trabalho ilustrado na Figura 6, o qual seguiu uma arquitetura de planejamento e controle similar ao de fabricação de peças.

0 PMO, nesse caso, foi responsabilizado por alimentar o sistema com novas solicitações de compra, gerenciar as prioridades entre a aplicação de recursos financeiros e de logística de transporte e desembaraço da empresa entre os diferentes itens para os diferentes

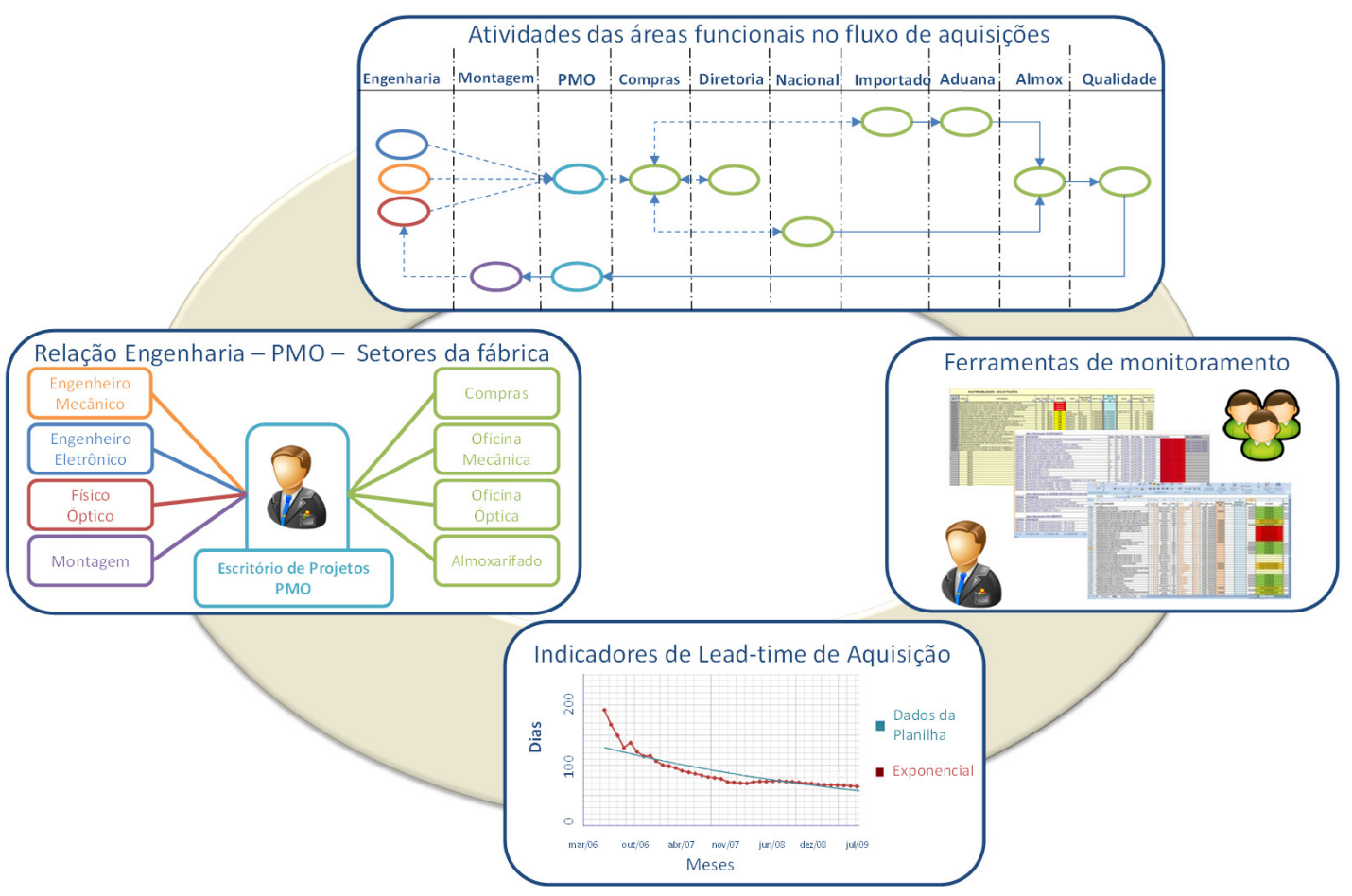

Figura 6. Esquema/estrutura de gestão de itens comprados para os projetos. 
projetos com base nos cronogramas desenvolvidos. Garante também a consecução de todas as atividades e a alimentação do sistema pelos departamentos e gerencia os indicadores de desempenho do processo. Assim como para as peças fabricadas, os gerentes de projeto foram responsabilizados por garantir prazos de liberação de especificações, especialmente com relação a itens de longo lead-time. É importante enfatizar que produtos de alta tecnologia têm forte demanda por itens importados, sem similar nacional, e são regulados pelos governos de seus países de origem, o que torna sua importação complexa e de alto risco para os prazos contratuais.

\subsection{Resultados alcançados em termos de indicadores de processo}

Segundo Carvalho (2011), os indicadores de gestão de projetos devem abranger eficiência e eficácia de forma complementar. Assim, analisam-se abaixo dados relativos à eficiência (laggingindicator) dos processos de gestão de insumos executados pelo PMO, e em seguida dados de duração dos projetos, principal indicador de eficácia (leadingindicator) dos projetos na empresa.

A Figura 7 apresenta dados de quantidade e de lead-time dos itens fabricados. No início da implantação do PMO, para cada desenho liberado para fabricação demorava-se, em média, 109 dias para entregar as peças para o pessoal de montagem e teste. Dezembro de 2005 foi o período de transição entre a fase sem formalização do fluxo de informações entre a engenharia e a manufatura para uma fase de utilização de um protocolo de entrega de documentos, iniciado em janeiro de 2006.

Entre janeiro e maio de 2006, o processo foi monitorado por meio de reuniões realizadas pelo PMO e formalizadas em atas. Utilizou-se e-mail como forma de controle de prazos intermediários entre os departamentos à medida que foi sendo mapeado o processo como um todo, o qual foi sistematizado entre os meses de maio e julho de 2006. A partir de julho de 2006, passou-se a utilizar a ferramenta desenvolvida em Excel para rastrear as atividades intermediárias entre os departamentos, conforme mencionado. A partir de então, os lead-times parcial e total da fabricação de cada item foram consolidados em gráficos disponibilizados mensalmente para os envolvidos, assim como utilizados para realizar melhorias no processo mapeado. 0 gráfico da Figura 7 apresenta a evolução do número de itens fabricados controlados por meio dessa sistemática, assim como a evolução de seu lead-time mensal. A quantidade de itens obedece à escala à esquerda na figura, enquanto o lead-time segue a escala da direita. Observa-se que, embora a quantidade de itens tenha aumentado numa proporção que chegou a 16 vezes o número inicial, o lead-time chegou a ser $2 \%$ do original em outubro de 2007 e abril de 2008.

A Figura 7 apresenta ainda a média móvel do lead-time de fabricação dos itens de protótipos de maneira a ilustrar graficamente o grau de melhoria conseguido nesse indicador. Assim sendo, a cada novo mês os valores do lead-time das peças concluídas no

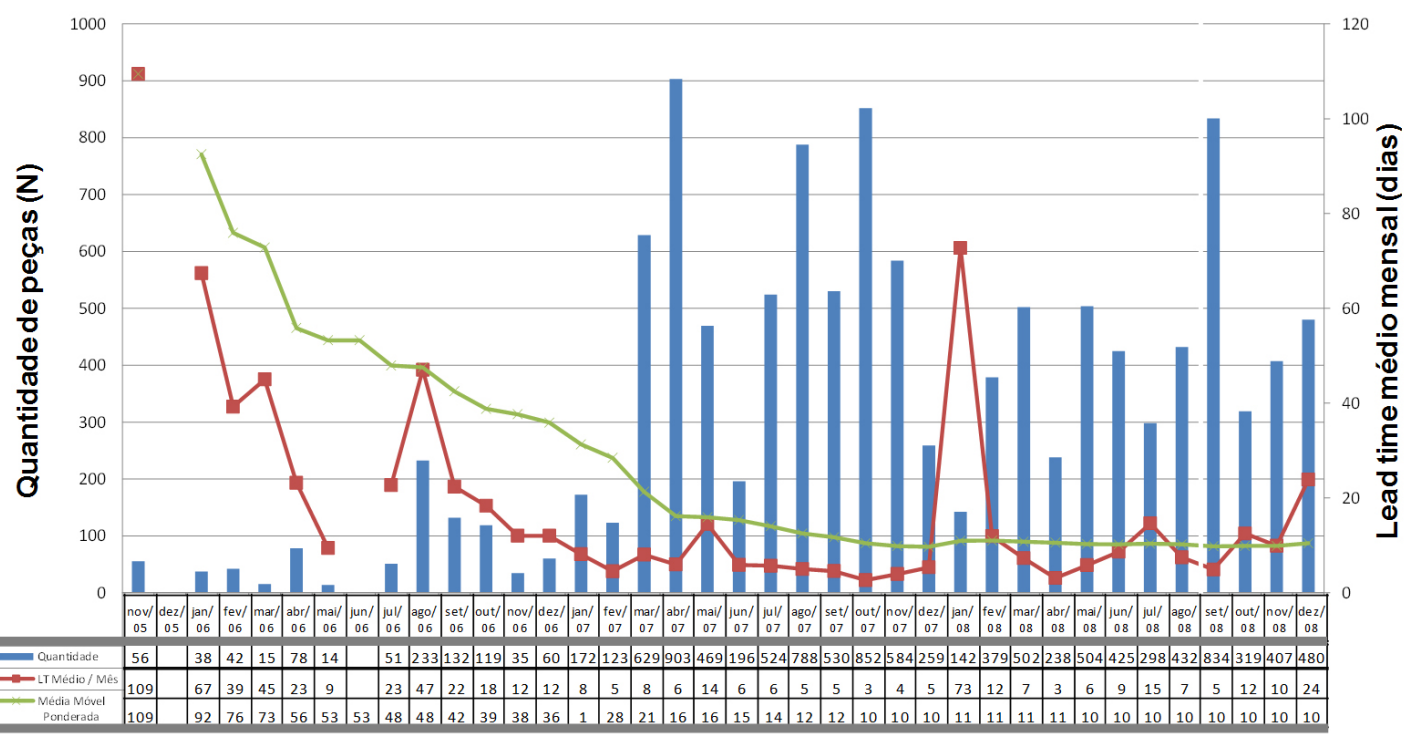

Figura 7. Desempenho do processo de fabricação de itens para projetos. 
mês, e a sua quantidade, eram incrementados aos valores acumulados de maneira a verificar a curva da média móvel. Observa-se que tal curva apresenta perfil decrescente sendo estabilizado após 24 meses de implantação do processo, a partir de novembro de 2007, onde o lead-time é da ordem de 10 a 11 dias para cada item fabricado. Como o enfoque do artigo não é o processo de fabricação mecânica, foge ao escopo detalhar as atividades de melhoria implementadas.

Similarmente, a Figura 8 apresenta dados de quantidades e lead-time dos itens comprados. No início da implantação do PMO, para cada item a ser adquirido demorava-se cerca de 190 dias em média para entregá-lo ao pessoal de projeto. Essa média chegou a um mínimo de 13 dias, enquanto a quantidade total de itens chegou a 8.199, muito embora apresente uma variação perceptivelmente grande ao longo do período.

A aquisição de itens para protótipos de projetos de alta tecnologia é fortemente dependente de uma variável tecnológica e de restrições governamentais que fogem ao controle dos operadores de compra dentro da empresa. Adicionalmente, as atividades e, consequentemente, os lead-times envolvidos em aquisições nacionais e importadas são ligeiramente diferentes entre si, o que reflete em variações no desempenho do processo. Por exemplo, no mês de novembro de 2007, no qual houve paralelamente o pico mínimo de lead-time e a maior quantidade de itens, houve uma decisão tomada pela engenharia em conjunto com o PMO em que aquisições que originalmente seriam importadas viraram compras nacionais e, portanto, com fluxo de trabalho mais simples e lead-times historicamente menores.

Na Figura 8 consta também a média móvel ponderada do lead-time de itens comprados ao longo do período pesquisado, calculada de maneira similar ao processo de fabricação. Observa-se tendência decrescente estabilizada a partir do mês 21 (abril de 2008) em uma faixa de 47-49 dias por item comprado.

A Figura 9 apresenta o indicador de eficácia adotado na empresa. Trata-se de um gráfico no qual estão consolidados dados de duração dos projetos em execuçãoao longo do período aqui considerado. São apresentados os dados com base no ano de início dos projetos que estavam em andamento quando da sistematização e implantação do escritório, assim como os iniciados após implantado o PMO.

Pode-se observar que a duração final dos projetos diminuiu em 2,3 vezes os prazos incorridos quando da introdução da sistemática aqui descrita. Se considerarmos o estudo de Ali et al. (1995), que analisou 73 PMEs de alta tecnologia americanas e chegou a uma média de 18,7 meses (560 dias) de duração dos projetos, conclui-se que as práticas de gestão de projetos da empresa analisada, além de reduzirem fortemente o tempo de mercado dos produtos, trouxeram os prazos de desenvolvimento para o patamar diagnosticado pelos autores acima.

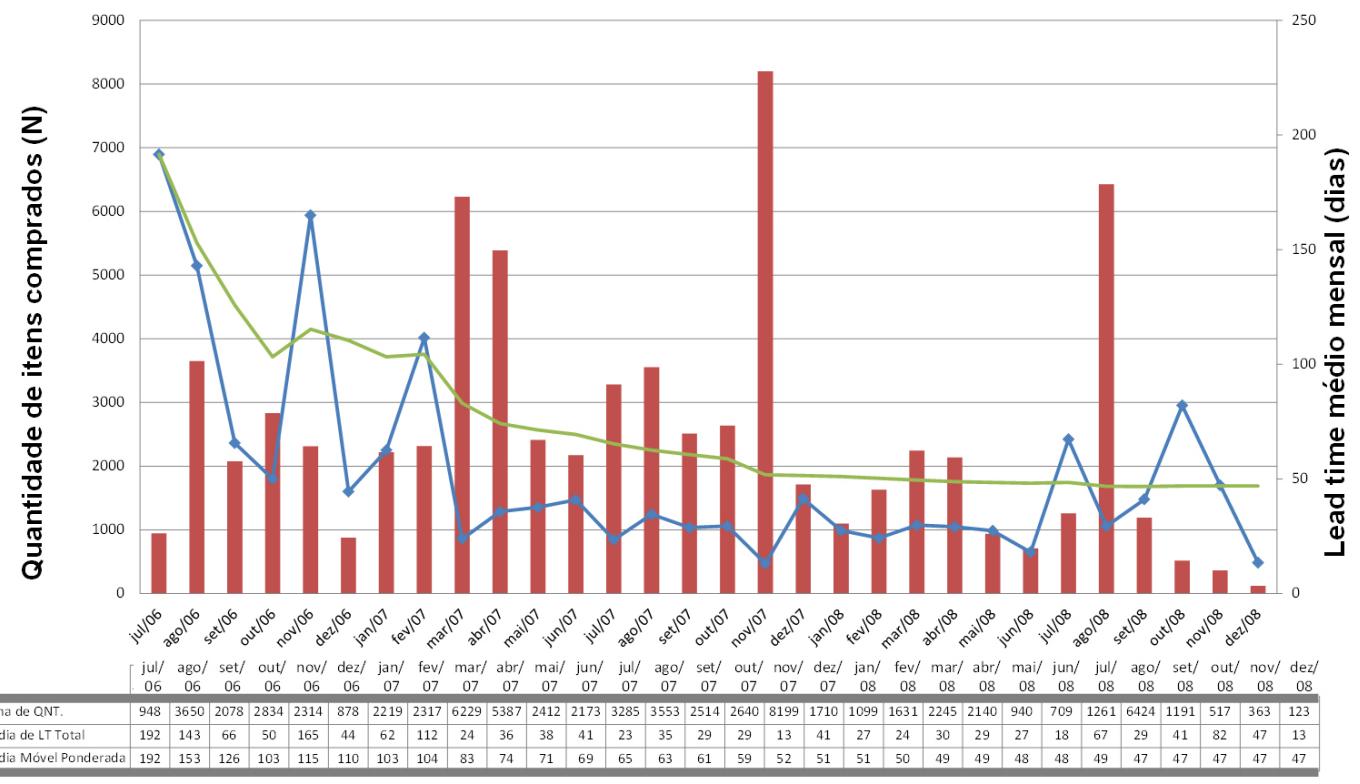

Figura 8. Desempenho do processo de aquisição de itens para projetos. 


\section{Análise comparativa do PMO descrito ante a literatura de referência}

Verifica-se então que o trabalho de implantação do PMO permitiu reduzir lead-times de processos relacionados à logística necessária aos projetos, além dos lead-times globais dos projetos. Uma vez que a configuração final do PMO ante as atividades do PDP diferia da literatura, foi realizada uma análise sistemática de maneira a caracterizá-lo. 0 estudo de Hobbs e Aubry (2007) foi utilizado como referência para realizar essa análise.

Aos agrupamentos descritos em Hobbs e Aubry (2007), apresentados na seção 2.2, foi acrescido o grupo Insumos representando a prática estabelecida pelo PMO estudado quanto à gestão de itens fabricados e adquiridos por meio de compra para os novos produtos. A comparação foi feita através da utilização das funções descritas pelos autores como checklist seguida da análise, por parte do pessoal do PMO, quanto ao grau de realização de cada uma das funções, conforme uma metodologia proposta pelo Capability Maturity Model Integration (CMMl, ver CHRISSIS et al., 2003), ilustrada na Figura 10, onde:

- Não faz - grau de realização 0. A função não é desempenhada pelo PMO;

- Faz - grau de realização 1. 0 PMO realiza a atividade, mas não há um planejamento prévio para sua execução;

- Planeja - grau de realização 2. A atividade é executada de acordo com um planejamento prévio;

- Método - grau de realização 3. A atividade é realizada conforme planejada, sendo baseada em um método e um conjunto de padrões e templates;

- Mensura - grau de realização 4. A atividade é realizada, sendo baseada em planejamento e método e seus resultados são medidos de forma a comparar as diferentes instâncias de sua execução;
- Otimiza - grau de realização 5. A atividade é continuamente melhorada através da identificação e eliminação das causas da variabilidade de seus resultados.

A Figura 11 apresenta um gráfico de radar comparativo entre a ocorrência dos grupos de funções dos escritórios de projetos encontrados pelos autores e as práticas do PMO analisado na empresa em questão.

Observa-se que as 500 empresas pesquisadas pelos autores canadenses apresentam um perfil de atividades com percentuais similares entre funções de desenvolvimento de competências e metodologias (METCOMP), monitoramento e controle (MONCON), gestão multiprojetos (MULTI) e aprendizagem organizacional (ORGLEARN), todas com cerca de $20 \%$ de ocorrência. Isso demonstra que juntas essas funções representaram uma média de $80 \%$ do trabalho dos PMOs, segundo a pesquisa dos autores. Já na empresa aqui pesquisada, o PMO tem na gestão de insumos (Insumos) sua principal função (26\%), seguida de aprendizagem (ORGLEARN), monitoramento e controle (MONCON) e desenvolvimento de metodologias (METCOMP). Observa-se que as áreas de metodologia, gestão multiprojeto e aspectos de estratégia têm bem menos impacto no trabalho do PMO aqui pesquisado quando comparado com o texto de referência, enquanto a gestão de insumos inexiste como atividade na pesquisa de Hobbs e Aubry (2007).

Os dados acima demonstram que o escritório aqui descrito apresenta uma diferenciação quanto à literatura da área. Esse dado, assim como os resultados de melhoria de lead-times apresentados anteriormente, aponta para uma variação na estruturação de PMOs que pode ser utilizada quando condições similares às aqui descritas ocorrerem gerando resultados positivos para o negócio.

\section{Duração Média dos Projetos por Ano de Início (em dias)}

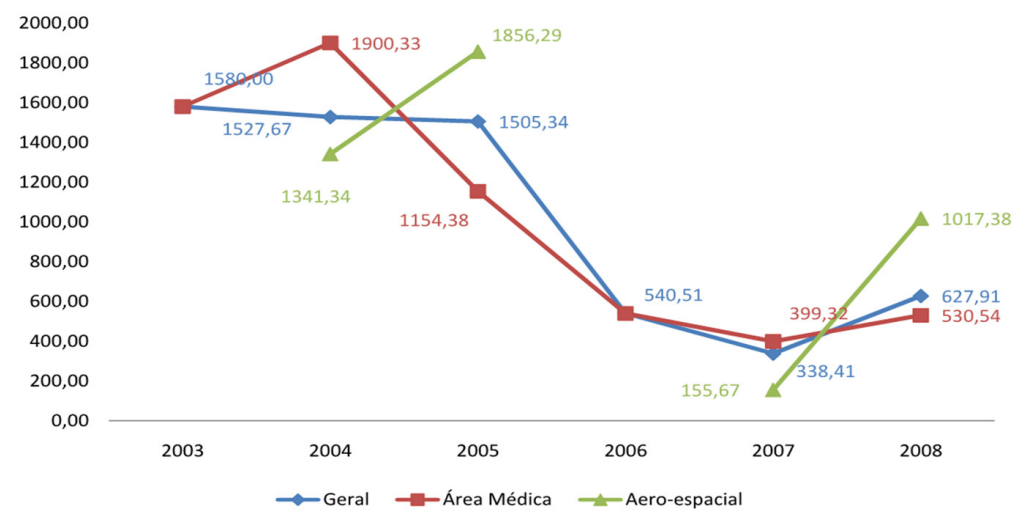

Figura 9. Resultados de desempenho dos projetos em termos de prazos. 


\begin{tabular}{|l|c|c|c|c|c|c|c|}
\hline \multirow{2}{*}{ Função do PMO } & \multicolumn{6}{|c|}{ Grau de realização } & \multirow{2}{*}{ Como é feito } \\
\cline { 2 - 8 } & $\begin{array}{c}\text { Não faz } \\
(0)\end{array}$ & $\begin{array}{c}\text { Faz } \\
\text { (1) }\end{array}$ & $\begin{array}{c}\text { Planeja } \\
\text { (2) }\end{array}$ & $\begin{array}{c}\text { Método } \\
\text { (3) }\end{array}$ & $\begin{array}{c}\text { Mede } \\
\text { (4) }\end{array}$ & $\begin{array}{c}\text { Otimiza } \\
\text { (5) }\end{array}$ & \\
\hline & & & & & & & \\
\hline
\end{tabular}

Figura 10. Escala de aferição do grau de realização das funções do PMO.

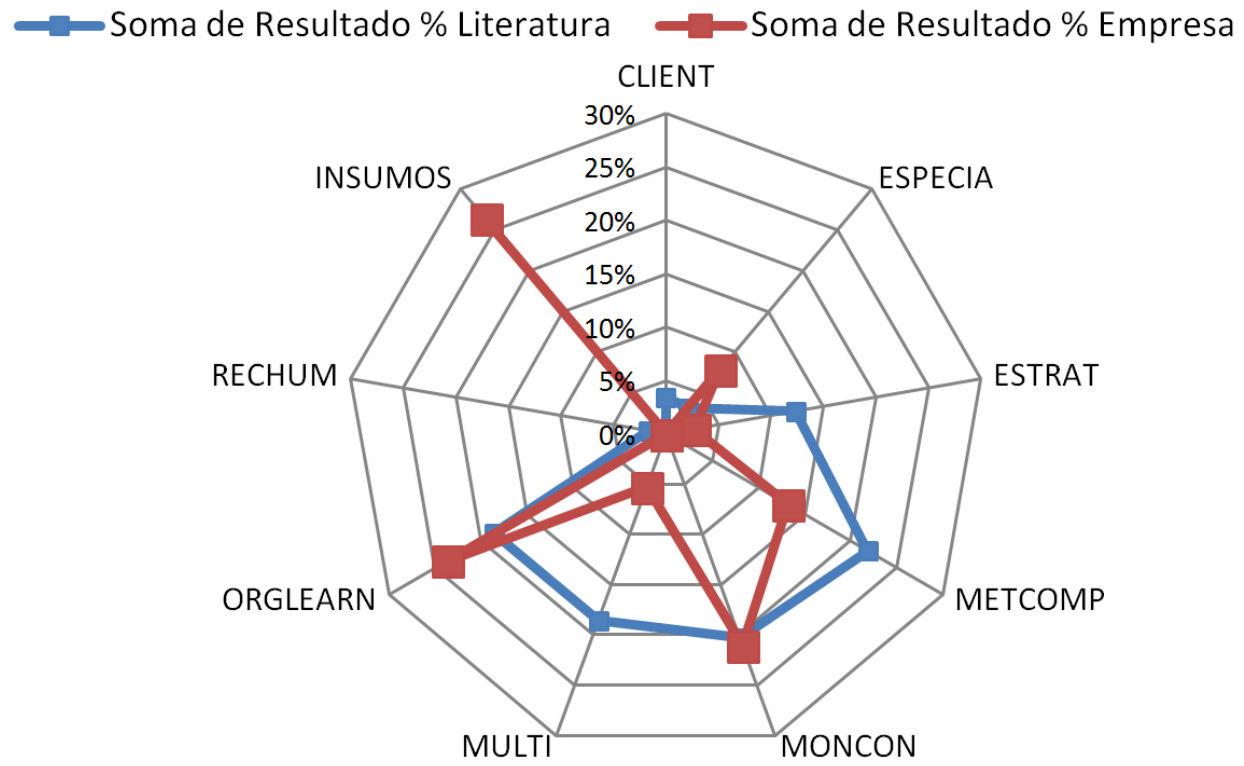

Figura 11. Radar comparativo das práticas do PMO estudado.

\section{Considerações finais}

As práticas tradicionais de gestão de projetos do PDP estabelecem que os gerentes e suas equipes devam desenvolver e manter os cronogramas dos projetos de maneira a realizar as entregas estabelecidas na estrutura da divisão do trabalho. Os escritórios de projetos são mais comumente definidos como entidades responsáveis pelo suporte e provisão de metodologias de gestão, do que pela realização de atividades gerenciais propriamente ditas. Embora sejam descritas práticas na literatura científica (ver item 2.2) da área onde alguns projetos, portfólios ou programas são gerenciados diretamente pelo PMO.

0 caso apresentado neste artigo expõe uma situação intermediária no qual o PMO é responsável pela gestão dos prazos dos projetos, mas não detém a autoridade sobre a gestão das equipes dos projetos, ou da divisão/alocação/acompanhamento das atividades do dia a dia de maneira a atingir os requisitos do produto/projeto. Porém, a gestão multiprojeto e a gestão de portfólio são realizadas ou fortemente influenciadas pelo PMO. Para tal, os recursos de produção e aquisições, aí incluídos máquinas, homens-hora de fabricação e gestão dos orçamentos dos projetos, são controlados pelo PMO mediante negociação com a diretoria de $\mathrm{P} \& \mathrm{D}$ e os gerentes de projeto. Por meio de tal sistemática, os resultados obtidos na empresa demonstram que houve considerável redução dos prazos dos projetos ao longo do período no qual o PMO passou a centralizar a gestão de tempo. A utilização de dados históricos e de um template com listas de atividades, precedências e durações, assim como o fato de o PMO deter conhecimento multiprojetos e incorporar tal conhecimento nas discussões de planejamento e monitoramento dos cronogramas, permitia programar atividades mediante as melhores práticas existentes na empresa. lsso pode explicar o fato de a duração dos projetos ter redução significativa ao longo dos seis anos analisados na Figura 9.

0 processo de implantação do escritório de projetos na empresa analisada durou cerca de 4 anos (período de 2005 a 2008). Ao longo desse período os processos que se apresentavam como necessários para a consecução dos projetos com êxito foram sendo elaborados e consolidadospelo PMO. A Figura 9 permite verificar que os projetos iniciados nesse período apresentam desempenho em prazo superior e, portanto, time-to-market bastante inferior aos projetos iniciados antes da implantação 
das práticas aqui descritas. Considera-se que isso se deveu ao fato de o PMO concentrar as informações de gestão dos projetos mantendo uma visão global do desempenho das equipes de engenharia. Ao mesmo tempo, gerenciava diretamente os processos mais críticos para o atendimento dos prazos dos projetos, ou seja, as etapas de fabricação de protótipos e de aquisições, as quais exigiam esforço integrativo e multidepartamental.

Embora não tenha sido analisado neste trabalho, considera-se que a sistemática de gestão de prazos centralizada na PMO pode implicar em dificuldades operacionais. Primeiro, a relação entre o PMO e os gerentes de projetos não é clara, pois, por um lado, o PMO fornece serviços ao gerente e, por outro, cobra resultados com base nos cronogramas de projeto. Essa duplicidade de papéis pode gerar problemas em ambas as pontas do processo: por um lado, o PMO pode sofrer por não ter um compromisso do gerente de projeto para com os prazos acordados para liberar as especificações de itens fabricados ou comprados. Por outro, os gerentes podem não ter seus itens disponíveis em função de não priorização de suas pendências por parte do PMO. Segundo, as interfaces do PMO com o restante da fábrica o tornam crítico para o andamento dos projetos, mas também fazem com que o escritório centralize insatisfações que podem ser de diversos projetos ou de diversos setores e, ainda, de todos ao mesmo tempo, com diferentes demandas e diferentes níveis de entendimento sobre os problemas de uma ponta ou de outra (da logística das peças e itens comprados ou da dinâmica do projeto em si).

Outro aspecto a considerar é que foi possível incorporar as funções de gestão de insumos no PMO porque a empresa considerada não contava com processos de fabricação, compras, planejamento e controle da produção, programação da produção etc. bem estruturados. Isso abriu uma possibilidade de ação do PMO na gestão dessas interfaces e, consequentemente, na proposição de procedimentos e ferramentas de gerenciamento desses processos. Possivelmente se a empresa tivesse os processos de gestão de insumos bem estruturados não haveria essa alternativa de atuação para o PMO. De qualquer forma, os resultados demonstram que esse tipo de atuação teve um impacto significativo nos tempos de mercado de projetos de novos produtos.

Enfim, o trabalho demonstra que os escritórios de projetos, comumente vistos como estruturas voltadas ao suporte aos gerentes de projeto, à gerência sênior e às equipes de projeto, podem assumir funções que estejam diretamente vinculadas à consecução dos objetivos dos projetos propriamente ditos. Demonstra ainda que, sendo o PMO responsável pela gestão das interfaces entre o projeto e a estrutura de fabricação e compras da empresa, incluindo a definição das prioridades entre os diversos projetos, é possivel melhorar indicadores de eficiência e de eficácia dos projetos. Essa é uma possibilidade prática importante para a estruturação dos PMOs em empresas desenvolvedoras de produtos.

Do ponto de vista científico, considera-se que à lista das funções do PMO descritas na bibliografia da área deve-se acrescentar o elemento "gestão de insumos" (ver seção 5). Tal construto permitiria absorver aspectos funcionais dos PMOs não abrangidos pela literatura vigente. Pesquisas futuras podem analisar a ocorrência desse tipo de atividade em escritórios de outras empresas desenvolvedoras ou que se utilizem de projetos para desenvolver outros tipos de atividade. Podem ainda enfocar as barreiras organizacionais enfrentadas por esse tipo de prática no cotidiano das empresas.

\section{Referências}

ALl, A. et al. Product innovativeness and entry strategy: impact on cycle time and break-even time. Journal of Product Innovation Mangament, v. 12, p. 54-69, 1995. http://dx.doi.org/10.1016/0737-6782(94)00027-D

ALVES, R. O. et al. Melhores práticas em implantação de escritório de gerenciamento de projeto: desenvolvimento de referenciais de sucesso. Produção. Ahead of print Epub Dec 07, 2012. http://dx.doi.org/10.1590/S010365132012005000094

AUBRY, M.; HOBBS, B. A fresh look at the contribution of project management to organizational performance. Project Management Journal, v. 42, n. 1, p. 3-16, Feb 2011 http://dx.doi.org/10.1002/pmj.20213

AUBRY, M. et al. ldentifying forces driving PMO changes. Project Management Journal, v. 41, p. 30-45, 2010a. http://dx.doi.org/10.1002/pmj.20191

AUBRY, M. et al. Project management offices in transition. International Journal of Project Management, v. 28, p. 766-778, 2010b. http://dx.doi.org/10.1016/j. ijproman.2010.05.006

AUBRY, M.; HOBBS, B.; THUILLIER, D. A new framework for understanding organizational project management through the PMO. International Journal of Project Management, v. 25, p. 328-336, 2007. http://dx.doi. org/10.1016/j.jproman.2007.01.004

BARON, R. A. et al. Empreendedorismo: uma visão do processo. São Paulo: Cengage Learning, 2011.

BREDILLET, C. N. Mapping the dynamics of the project management field: Project management in action (part 6). Project Management Journal, v. 41, n. 2, p. 2-4, Apr 2010. http://dx.doi.org/10.1002/pmj.20177

CARVALHO, M. M. Sistemas de indicadores de sucesso em projetos. Mundo Project Management, v 7, n. 41, p. 9-17, Oct/Nov 2011.

CASTRO, H.; CARVALHO, M. M. Project management best practices implementation: critical issues in telecommunication companies. Product: Management \& Development, v. 5, n. 1, June 2007. 
CHRISSIS, M. B. et al. CMMI: Guidelines or process integration and product improvement. Boston: AddisonWesley, 2003.

CLARK, K. B.; FUJIMOTO, T. Product development performance: strategy, organization and management in the world auto industry. Boston: Harvard Business School Press, 1991.

COOPER, R. G. Winnig at new Products: Accelerating the process form idea to launch. 3rd ed. Basic Books, 2001.

COUGHLAN, P.; COUGHLAN, D. Action research for operations management. International Journal of Operations \& Production Management, v. 22, n. 2, p. 220-240, 2002 http://dx.doi.org/10.1108/01443570210417515

CRAWFORD, L. The strategic project office. New York: Marcel Dekker, 2002.

DAl, C. X.; WELLS, W. G.An exploration of project management office features and their relationship to project performance. International Journal of Project Management, v. 22, p. 523-532, 2004. http://dx.doi. org/10.1016/j.jproman.2004.04.001

HOBBS, B.; AUBRY, M. A multi-phase research program investigating project management offices (PMOs): the results of phase 1. Project Management Journal, v. 38, n. 1, p. 74-86, Mar 2007.

HOBBS, B.;AUBRY, M.; THUILLIER, D.The project management office as an organisational innovation. International Journal of Project Management, v. 26, p. 547-555, 2008. http://dx.doi.org/10.1016/j.jproman.2008.05.008

MARTINS, A. P. et al. Implantação e consolidação de escritório de gerenciamento de projetos: um estudo de caso. Produção, v. 15, n. 3, p. 404-415, set./dez. 2005. http://dx.doi.org/10.1590/S0103-65132005000300010

MAXIMIANO, A. C. A.; ANSELMO, J. Escritório de gerenciamento de projetos: um estudo de caso. Revista de Administração, v. 41, n. 4, p. 394-403, 2006.

PELLEGRINELLI, S.; GARAGNA, L. Towards a conceptualisation of PMOs as agents and subjects of change and renewal. International Journal of Project Management, v. 27, n. 7, p. 649-656, 2009. http://dx.doi.org/10.1016/j. ijproman.2008.12.001

PONS, D. Project management for new product development. Project Management Journal, v. 39, n. 2, p. 82-97, 2008. http://dx.doi.org/10.1002/pmj.20052

PROJECT MANAGEMENT INSTITUTE - PMI. Project Management Body ofKnowledge - PMBOK. 5rd ed. 2012.

PUGH, S. Total design. London: Addison Wesley, 1990.

RODRIGUES, 1.; RABECHINI JUNIOR, R.; CSILLAG, J. M. Os escritórios de projetos como indutores de maturidade em gestão de projetos. RAUSP. Revista de Administração, v. 41, n. 3, p. 273-287, jul./ago./set. 2006.

ROZENFELD, H. et al. Gestão de Desenvolvimento de Produtos. São Paulo: Editora Saraiva, 2006.

SERVA, M.; JAIME JÚNIOR, P. Observação participante e pesquisa em administração. Revista de Administração de Empresas, v. 35, n. 1, p. 64-79, 1995. http://dx.doi. org/10.1590/S0034-75901995000300008

THIOLlENT, M. Pesquisa-ação nas organizações. São Paulo: Editora Atlas, 1997.

YIN, R. Estudo de caso. Tradução de Daniel Grassi. Revisão de Cláudio Damacena. 2. ed. Porto Alegre: Bookman, 2004.

\title{
Functions of project management offices in product development: action research in a high-tech company
}

\begin{abstract}
The article presents a Project Management Office (PMO) for supporting project management activities in new product development (NPD). The established practices centered on PMO activities differ from the functions that characterize them, as described in the literature. The functions performed are material planning and control, which are activities that provide projects with the materials and components necessary for the assembly of prototypes and products. The functions of the PMO are compared to the activities listed in the bibliography. The indicators of efficiency and effectiveness of projects are presented. There was a reduction of lead times by $90 \%$ in manufacturing and by $75 \%$ in purchases. The duration of projects decreased by $43 \%$. The role assumed by the PMO can enhance the theoretical options for structuring Project Management Offices in NPD.
\end{abstract}

Keywords

New product development. Project management. Project management offices. 